\title{
The Correlation between Elementary School Principals' Servant Leadership and Teachers' Creative Teaching Behavior
}

\author{
Cheng-Ping Chang1, Hung-Chih Tsai², Dan-Dan Zhang ${ }^{3}$, I-Jun Chen ${ }^{*}$ \\ ${ }^{1}$ Department of Education National University of Tainan, Taiwan \\ ${ }^{2}$ Department of Finance and Banking, Kunshan University, Taiwan \\ ${ }^{3}$ School of Business, Macau University of Science and Technology, Macau, China \\ ${ }^{4}$ Department of Psychology, College of Education, Soochow University, Soochow, China \\ Email: "herbchen66@163.com
}

Received 16 May 2016; accepted 17 June 2016; published 21 June 2016

Copyright (C) 2016 by authors and Scientific Research Publishing Inc.

This work is licensed under the Creative Commons Attribution International License (CC BY).

http://creativecommons.org/licenses/by/4.0/

(c) (i) Open Access

\begin{abstract}
This study's research objectives are investigating the status and understanding the correlation between creative teaching behavior, and school principals' servant leadership at elementary schools in Tainan City's rural and remote areas. On research method, questionnaire was designed and the objects of this study were the public elementary school teachers within the Taiwan. Data analysis was conducted for the 723 effective questionnaires from 84 schools. The valid return rate was $85 \%$. Research findings are shown as follows: There is positive correlation between school principals' servant leadership and Creative teaching behavior.
\end{abstract}

\section{Keywords}

Elementary School, School Principals' Servant Leadership, Creative Teaching Behavior

\section{Introduction}

Humans have progressed from an era of industrial revolution to an era of information revolution. Taiwan's economic structure has also transformed from being labor intensive to facing challenges in an era of the knowledge economy. In order to improve a nation's competitiveness, the government of any nation faces the importance of creativity squarely. Schools are key organizations which educate and cultivate a nation's future talent, play the role of driving a nation's social and economic development, and shoulder the hefty responsibility of developing

${ }^{*}$ Corresponding author.

How to cite this paper: Chang, C.-P., Tsai, H.-C., Zhang, D.-D., \& Chen, I.-J. (2016). The Correlation between Elementary School Principals' Servant Leadership and Teachers' Creative Teaching Behavior. Creative Education, 7, 1253-1260.

http://dx.doi.org/10.4236/ce.2016.79132 
and cultivating a nation's creativity. When it comes to issues about the development and enhancement of students' creativity, many studies found that teachers' creative teaching behavior has the function of enhancing students' creativity. Creative teaching could arouse students' creativity, improve students' creativity in the cognitive, psychomotor, and affective domains, as well as help creativity-related abilities such as imagination, association, thinking, a sense of humor, and the utilization of creative techniques (Beghetto \& Kaufman, 2011; Cachia \& Ferrari, 2010; Schacter \& Thum, 2004). Hanushek (2002) and Sawyer (2011) found that in the course of creative teaching, students demonstrated improvements in an assortment of novel and effective scientific creativity. As such, teachers' creative teaching behavior is of significant importance for the development of students’ creativity.

According to the research by Lin (2006) on Taiwan's elementary school teachers, teachers perceived that the importance that a "school manager" and "other school teachers" attach to creative teaching and the cultivation of creativity, as well as the encouragement that they give to creative teaching and the cultivation of creativity, are positively correlated to teachers' intrinsic motivation for creative teaching and behavior. In particular, "school managers' attention and encouragement” could best predict teachers’ creative teaching behavior. Verification by means of structural equation modeling also found that "school gatekeepers' attitude toward creativity" could affect teachers' creative teaching by way of teachers' intrinsic motivation for creative teaching. The more importance that school creativity gatekeepers attach to creative teaching and the cultivation of creativity, the more likely teachers' intrinsic motivation for creative teaching would be aroused, and teachers would be more inclined to demonstrate creative teaching. Therefore, school principals are key leaders in advocating and encouraging school teachers' creative teaching behavior. From Greenleaf's point of view, a great leader has to be a man who serves other people first. The style of servant leadership brings the responsibility of serving other people to a manager's mind (Sergiovanni, 2000). Recently, many scholars have started to face servant leadership directly. Russel and Stone (2002) pointed out that a leader should have the drive to serve other people, personal interest shouldn't be the reason for servant leadership, and the focus of servant leadership should be other people's needs. The research by Greenleaf (2002) believed that servant leadership should put a priority on serving other people. It should originate from an individual's natural urge to serve other peoples, and a leader should consciously aspire to lead other people and step forward to lead other people toward a goal.

In addition, education is, perhaps, humanity's project of hope. It has the function of helping the human race sustain itself and prompts human and societal development. It is also the motivation for the human race's progress and the foundation for nations to be built. However, as rural and remote areas are subject to the influence of geographical and environmental factors such as inconvenient transport, a small population size, and poor economies, schools in these areas are relatively disadvantaged, which is not only unfavorable for the effective popularization of education but also compromising school children's opportunity to receive a good education. On the other hand, given a high turnover rate of school principals and teachers in rural and remote areas and an increased ratio of substitute teachers as a result of the local government's curb on the total teacher number due to a low birth rate, having consistent teaching quality becomes impossible. Tainan, which used to be “Taiwan's most fertile and richest region", has faced shrinking economic activities in its mountainous areas and a shortage of resources in the past few years. Besides, the central government has been favoring North Taiwan over South Taiwan for a long time, which would be a severe challenge for the greater Tainan area in the future. However, despite an array of disadvantaged conditions, we should never slight and give up on opportunities and the futures of disadvantaged children in rural and remote areas.

In line with the abovementioned research background and motivation, this study's research objectives is to understand the correlation between school principals' servant leadership and teachers' creative teaching behavior at elementary schools in Tainan City's rural and remote areas.

\section{Literature Review}

\section{School principals' servant leadership}

According to how the Greenleaf Center for Servant Leadership defined “servant leadership”, servant leadership is a philosophy of action, which advocates that people should put a priority on serving other people and further spread the approach of providing services to individuals or organizations. Servant leadership encourages collaboration, trust, long-term vision, listening, the right to use ethics, and empowerment. Different from other types of leadership, a leader of an organization or an institution has to make co-decisions with other people, 
demonstrate love, care, and empathy to subordinates, be a good listener to subordinates, encourage subordinates’ learning and growth, as well as honor subordinates' achievements. Servant leadership stress that members in an institution must cherish one another, value the worth of individuals' existence, and a leader must touch subordinates' souls so as to arouse subordinates' talent and skills in a favorable atmosphere.

The basic connotation of servant leadership is that providing services to organization members and a higher-order intrinsic need would prompt an individual and other organization members to develop a sense of achievement and self-actualization subsequently. There have been some results in the development of a servant leadership inventory. The servant leadership inventory developed which is based on 10 important personality traits of those who lead by the servant leadership proposed by Spears (1998), was developed after scrutinizing and integrating the essence of other servant leadership inventories, making modifications, adaptations, and conducting a pilot study. As revealed by results of an analysis of the servant leadership inventory's internal consistency, the value of Cronbach's $\alpha$ coefficient is .97 and the correlation coefficient value is .81 - .94. Henceforth, this study set out to collect data by using this servant leadership inventory as a reference.

\section{Creative teaching behavior}

Simonton (2012) proposed that creative teaching behavior refers to teachers' employment of diverse and energetic approaches as well as a variety of content in teaching to arouse students' intrinsic motivation to learn, cultivate students' enthusiasm about learning, and enhance students’ ability to learn. Bramwell, Reilly, Lilly, Kronish and Chennabathni (2011) proposed that teachers have demonstrated creative teaching behavior when: teachers utilize their own creative thinking to solve problems in teaching, carrying out their teaching job duties, and design valuable teaching activities to instruct students to learn relevant knowledge and skills.

The investment theory of creativity (Sternberg \& Lubart, 1995) believes that novelty and appropriate creativity are two essential elements of a creative product. An interaction model proposed by Gardner (1993) believes that a creative individual is capable of solving problems constantly, making products, and defining new problems in a professional field. Csikszentmihalyi (1988) proposed and developed the system of three creativity elements, including the DIFi (Domain Individual Field interaction) systems model, based on the definition of creativity. This model shows that creativity exists in the interaction between the three subsystems: individuals, fields, and academic disciplines. Proposing a framework about individual-environment interactions, Simonton (1995) stressed that environment would affect individual behavior and other people's attribution, the interaction of which would have both cross-sectional and longitudinal impacts. Overall, individuals are subject to the influence of the interaction between themselves and circumstantial scenarios. In the model of ecological systems, Yeh (2006) proposed the ecological systems model of creativity development, which comprises four systems: a small system, a medium system, an external system, and a large system. The Amusement Park Theoretical (APT) model of creativity proposed by Kaufman and Baer (2005) uses an amusement park's themed areas to allegorize five levels of the learning of creativity. It is the latest proposed theory of creativity.

With reference to theories of creativity proposed by Amabile, Sternberg, Guilford and Runco, Cheng (2001) inferred that five dimensions can be used to define and measure creativity in teaching. Taking a constructivist approach, Cheng (2001) believed that teachers' creativity in teaching could be evaluated by professionals, teachers themselves, students, and colleagues, and further developed a "teaching creativity inventory". With reference to Cheng's constructivist approach and methods of evaluation, Huang (2006) believed that the demonstration of teachers' creative teaching behavior could be evaluated by means of teachers' self-report. As such, after reviewing local and overseas scholars' research results and referring to teaching strategies, teaching principles, and behavior characteristics and meanings consolidated by these scholars, Huang (2006) concluded that the following five indicators are more often mentioned by one or more scholars together: 1) having interaction and discussion to encourage thinking; 2) being open-minded to learn the meaning of matters; 3) solving problems and stimulating imagination; 4) employing diverse teaching approaches to trigger students’ motivation; and 5) encouraging autonomous learning and giving challenges. These five indicators are used to design creative teaching instruments and further make a "creative teaching behavior inventory". Three hundred and twenty teachers from public junior high schools in Kaohsiung City were chosen as research participants, and Cronbach's $\alpha$ coefficient was used to examine the internal consistency of factors and the inventory's content. The result is that the general inventory's Cronbach's $\alpha$ coefficient is .92, and all factors' Cronbach's $\alpha$ coefficients are between .70 and .80, and the correlation coefficients of the general inventory and all sub-inventories all reach a .01 significance level, indicating the inventory's good internal consistency and reliability. Therefore, this inventory is chosen as a reference and basis for this study's measurement instrument. 


\section{Research and hypothetical reasoning of the correlation between variables}

As discovered by Lin (2006)'s research on middle school and elementary schools in Taiwan, teachers' perception of school managers' encouragement for creative teaching and the cultivation of creativity is positively associated with teachers' intrinsic motivation for creative teaching and creative teaching behavior. Verification by using the structural equation modeling technique also reveals that "school gatekeepers' attitude toward creativity" could affect teachers' creative teaching through "teachers' intrinsic motivation for creative teaching". Also, the more school creativity gatekeepers are inclined to encourage and value creative teaching and the cultivation of creativity, the more likely teachers' intrinsic motivation for creative teaching would be aroused and the more likely teachers are inclined to show creative teaching. A discovery from Chiu (2002)'s research on a creative atmosphere is that school principals' "gatekeeper" role had a quite important and direct influence on teachers' creative behavior. Therefore, this study made a daring assumption that there is a positive correlation between servant leadership of elementary school principals in Tainan City's rural and remote areas and teachers' creative teaching behavior.

\section{Research Design and Method}

\section{Research subjects and sampling}

In line with the research purposes, this study chose teachers at elementary schools in Tainan's rural and remote areas as research participants. With teachers at elementary schools in Tainan's rural and remote areas as the research population, this study further carried out a pilot study and an official questionnaire survey. Questionnaire copies were distributed by following an overview of elementary schools in 2014, which was promulgated on the Bureau of Education of Tainan City Government, as a guideline. At present, there are a total of 212 elementary schools in Tainan City, and 84 schools are located in rural and remote areas. For the pilot study, all teachers in Tainan Municipal Andian Elementary School and Tainan Municipal Chang-an Elementary School weare chosen as research participants and invited to fill out a pilot study questionnaire. A total of 46 pilot study questionnaire copies were returned and 45 copies are valid, making a $96 \%$ valid questionnaire response rate. As for the official questionnaire, teachers at elementary schools in Greater Tainan's rural and remote areas were chosen as research participants. Copies of the official questionnaire were handed out, 736 copies were returned, and 723 copies are valid, making an $85 \%$ valid questionnaire response rate.

\section{Research tools}

In terms of the demographic variables, the questionnaire contains questionnaire respondents' basic information, which includinges gender, marital status, age, seniority, the highest level of education, and current job title, such as "in Table 1", for the purpose of understanding attributes of data provided by the questionnaire respondents so that further analysis could be carried out.

"The school principals' servant leadership inventory" consists of five aspects, which are "listening to and showing empathy toward other people and serving people", "self-observation and self-discipline", "being capable to manage a school", as well as "encouraging and motivating school teachers and students". "The school principals' servant leadership inventory" is a self-report inventory which is rated by using a 5-point Likert scale. Research participants are instructed to select a suitable answer according to their perceived real scenarios. A teacher's total inventory score is positively correlated to the level of the teacher's self-reported creative teaching behavior. Meanwhile, as indicated by results of an internal consistency analysis, the Cronbach's $\alpha$ coefficient is .97, and the correlation coefficient is between .81 and .94.

The main purpose of the "creative teaching behavior inventory" is to measure the extent of teachers' creative teaching behavior. The inventory consists of five elements, which are "having interaction and discussion to encourage thinking, "being open-minded to learning the meaning of matters, "solving problems and stimulating imagination", "employing diverse teaching approaches to trigger students' motivation", and "encouraging autonomous learning and giving challenges". This study adopted a self-report inventory, which is rated by using a 5-point Likert scale. Research participants are instructed to select a suitable answer according to their perceived real scenarios. A teacher's total inventory score is positively correlated to the level of the teacher's self-reported creative behavior. The original inventory's Cronbach's $\alpha$ coefficient is .92, and each factor's Cronbach's $\alpha$ coefficient value is between .70 and .80 .

Research instruments' validity and reliability

The KMO value of "the school principals' servant leadership inventory" is .868 ( $<<.001)$, which is close to 1 , 
Table 1. Variable table.

\begin{tabular}{|c|c|c|c|}
\hline Variable & Item & Number & $\%$ \\
\hline \multirow{2}{*}{ Gender } & M & 266 & 36.8 \\
\hline & F & 457 & 63.2 \\
\hline \multirow{3}{*}{ Marital Status } & Married & 472 & 65.3 \\
\hline & Single & 244 & 33.7 \\
\hline & Other & 7 & 1.0 \\
\hline \multirow{5}{*}{ Age } & Under 25 & 18 & 2.5 \\
\hline & $26-35$ & 235 & 32.5 \\
\hline & $36-45$ & 282 & 39.0 \\
\hline & $46-55$ & 183 & 25.3 \\
\hline & $56 \mathrm{Up}$ & 5 & .7 \\
\hline \multirow{5}{*}{ Seniority } & $1-5$ years & 143 & 19.8 \\
\hline & 6 - 10 years & 128 & 17.7 \\
\hline & 11 - 15 years & 179 & 24.8 \\
\hline & $16-20$ years & 92 & 12.7 \\
\hline & 21 years and over & 181 & 25.0 \\
\hline \multirow{6}{*}{$\begin{array}{l}\text { Highest level of } \\
\text { education }\end{array}$} & College (Education) & 64 & 8.9 \\
\hline & College & 120 & 16.6 \\
\hline & Graduate School & 76 & 10.5 \\
\hline & Graduate School (Education) & 67 & 9.3 \\
\hline & Normal University & 236 & 32.6 \\
\hline & Graduate School (Normal) & 160 & 22.1 \\
\hline \multirow{3}{*}{ Current job title } & Concurrent Director & 260 & 36.0 \\
\hline & Concurrent Advisor & 316 & 43.7 \\
\hline & Teacher & 147 & 20.3 \\
\hline
\end{tabular}

indicating a good correlation coefficient and the suitability of factor analysis. The Bartlett test of sphericity approximate chi-square is 922.795 , which reaches significant difference. Meanwhile, given that the level of significance is bigger than 0 , and there are common factors, the data are suitable for factor analysis. The factor analysis resulted in three factors. Except for the first factor, other factors weare deleted for having fewer than three question items. Factor loadings of each question item on the inventory are between .657 and .876, and the accumulated explained variance is 34.226. Based on this, a factor "school principals' servant leadership", which consists of 19 question items, is generated. Further, Cronbach's $\alpha$ coefficient is used to examine the factor and the inventory's internal consistency. As revealed by an analysis of the variable inventory's reliability, the factor school principals' servant leadership's Cronbach's $\alpha$ coefficient is .964 and the sum of the variable's Cronbach's $\alpha$ coefficient is .964, indicating the inventory's good reliability. See Table 2.

The KMO value of "the creative teaching behavior inventory" is .747 $(p<.001)$, which is close to 1 , indicating a good correlation coefficient and the suitability of factor analysis. The Bartlett test of sphericity approximate chi-square is 311.950, which reaches significant difference. Meanwhile, given that the level of significance is bigger than 0 , and there are common factors, the data are suitable for factor analysis. Factor loadings of each question item on the inventory are between .381 and .764 , and the accumulated explained variance is 16.410. Based on this, a factor "teachers' creative teaching behavior", which consists of 13 question items, is generated. Further, Cronbach's $\alpha$ coefficient is used to examine the factor and the inventory's internal consistency. As revealed by an analysis of the variable inventory's reliability, the factor teachers' creative teaching behavior's Cronbach's $\alpha$ coefficient is .867 and the sum of the variable's Cronbach's $\alpha$ coefficient is .867 , indicating this inventory's good reliability. 
Table 2. The instruments' validity and reliability.

\begin{tabular}{ccccc}
\hline Variable & Question items & The accumulated explained variance & Factor loadings & $\alpha$ value \\
\hline Principal's servant leadership & 19 & 34.226 & $.657-.876$ & .964 \\
Creative teaching behaviors & 13 & 38.327 & $.649-.920$ & .9 .43 \\
\hline
\end{tabular}

\section{Results and Discussion}

\section{Results}

The overall mean score of school principals' servant leadership is 3.961, which is rated as a moderate-to-high level, indicating that school principals' servant leadership performance is perceived by school teachers as average-to-good and school principals' servant leadership performance is good based on participatory teachers' perception. It also indicates that school principals had the ability to utilize different methods in school management, respect school teachers, think from school teachers' point of view, understand each school teacher's strengths, and collaborate with school teachers to promulgate and carry out school matters. The overall mean score of teachers' creative teaching behavior is 4.040, which is rated as a moderate-to-high level, indicating thates school teachers' average-to-good performance of creative teaching behavior and participatory teachers' good creative teaching behavior. It also indicates that participatory teachers would create an energetic and open atmosphere for learning, provide novel and an assortment of teaching materials, and have the ability to arrange slightly more challenging assignments which suit students' ability. Means and standard deviations of this study's research on school principals' servant leadership and teachers' creative teaching behavior are presented in Table 3.

As shown in Table 4, the overall correlation coefficient between school principals' servant leadership and teachers' creative teaching behavior is .288 $(p<.01)$, indicating a significant and low correlation. It also means that there is a significant positive correlation between school principals' overall servant leadership and teachers' overall creative teaching behavior. Therefore, we can infer that teachers' creative teaching behavior is proportional to school principals' servant leadership. Additionally, school principals' servant leadership makes a positive influence on teachers' creative teaching behavior. Therefore, the assumption is validated.

\section{Discussion}

Csikszentmihalyis (1988) developed a three-indicator systems model comprised of individuals, fields, and disciplines. In other words, creativity is generated through the interaction between individuals, products, and surrounding environments. In particular, individuals' and gatekeepers' influence on creativity, which is related to this study, also plays an important role. Lin (2006) mentioned that the intrinsic motivation for teachers' creative teaching comes from teachers' passion for teaching, readiness to accept teaching challenges, and endeavor to look for solutions. Seligman (2003) put forward that positive emotions could expand human wisdom and boost creativity.

According to Lin's (2006) research on junior and elementary school teachers in Taiwan, the level of teachers' perception of school managers' value on and encouragement for creative teaching and the cultivation and creativity is positively correlated to teachers' intrinsic motivation for creative teaching and creative teaching behavior. According to Chiou's (2002) research on creative atmosphere, the performance of school principals' role as gatekeepers had a very important and direct influence on teachers' creative behavior. Therefore, the result that school principals could affect school teachers' innovative and creative behavior bears a resemblance to this study's result. Bowman (2005) and Jennings and Stahl-Wert (2003) pointed out that the purpose of servant leadership is to encourage creative behavior.

\section{Conclusion and Suggestions}

Servant leadership of school principals at disadvantaged elementary schools in Tainan City's rural and remote areas is positively correlated to teachers' creative teaching behavior. School principals should take a servant approach to lead school teachers so as to improve teachers' psychological feelings and subsequently foster teachers' creative teaching behavior. To avoid different research results resulting from an insufficient number of research participants and a small research sample, future researchers may expand the research population to teachers all across the country, or even conduct a cross-cultural comparison of research participants in different countries and a cross-industry investigation. The questionnaire survey method is this study's main research method for data collection. However, future research may supplement results of quantitative research and analysis with 
Table 3. The mean and standard deviation of each variable $(\mathrm{N}=723)$.

\begin{tabular}{|c|c|c|c|}
\hline Variable & Mean & Standard Deviation & Question Items \\
\hline Principal's servant leadership & 3.961 & .809 & $\begin{array}{c}1,2,3,4,5,6,7,8,9,10 \\
11,12,13,14,15,16,17,18,19\end{array}$ \\
\hline Creative teaching behaviors & 4.040 & .537 & $\begin{array}{c}1,2,3,4,5,6,7,8,9,10 \\
11,12,13\end{array}$ \\
\hline
\end{tabular}

Table 4. An analysis of the correlation between teachers' psychological wellbeing, school principals' servant leadership, and teachers' creative teaching behavior $(\mathrm{N}=723)$.

\begin{tabular}{lcc}
\hline & Variables & Principal's servant leadership \\
\hline Creative teaching behaviors & The significance of correlation coefficient & $.288^{* *}$ \\
.000
\end{tabular}

${ }^{* *} p<.01$.

qualitative research to enhance the depth of research. Through conducting one-on-one and in-depth interviews with research participants from different directions and perspectives, qualitative research methods not only enable the cross-verification of quantitative analysis and qualitative investigation but also enhance the comprehensiveness of research results and inferences and even discover the specific reason why a class atmosphere's moderating effect is not supported in this study.

\section{References}

Beghetto, R. A., \& Kaufman, J. C. (2011). Teaching for Creativity with Disciplined Improvisation. In R. K. Sawyer (Ed.), Structure and Improvisation in Creative Teaching. New York: Cambridge University Press. http://dx.doi.org/10.1017/CBO9780511997105.006

Bowman, R. F. (2005) Teacher as Servant Leader. The Clearing House: A Journal of Educational Strategies, 78, $257-260$.

Bramwell, G., Reilly, R. C., Lilly, F. R., Kronish, N., \& Chennabathni, R., (2011). Creative Teacher. Roeper Review, 33, 228-238. http://dx.doi.org/10.1080/02783193.2011.603111

Cheng, M. Y. V. (2001). Creativity in Teaching: Conceptualization, Assessment and Resources. Unpublished Doctoral Dissertation of Hong Kong Baptist University.

Chiou, H. J. (2002). The Construct of the Campus Organizational Climate for Creativity and the Teachers' Creativity Performance: Another "New Cloth of the King”? Applied Psychology Research, 15, 191-224.

Csikszentmihalyi, M. (1988). Flow: The Psychology of Optimal Experience. New York: Harper \& Row. http://dx.doi.org/10.1017/CBO9780511621956

Gardner, H. (1993). Creating Minds. New York: Basic Books.

Greenleaf, R. K. (2002). Servant-Leadership: A Journey into the Nature of Legitimate Power and Greatness. Mahwah, NJ: Paulist Press.

Hanushek, E. A. (2002). Teacher Quality. In L. T. Izumi, \& W. M. Evers (Eds.), Teacher Quality (pp. 1-12). Palo Alto, CA: Hoover Press.

Huang, H. C. (2006). The Relationships between Demographic Variables, Playfulness, Motivation of Teaching, Happiness and Creative Teaching among Junior High School Teachers. Kaohsiung: National Sun Yat-Sen University.

Jennings, J., \& Stahl-Wert, J. (2003). The Serving Leader. San Francisco: Berrett-Koehler.

Kaufman, J. C., \& Baer, J. (2005). The Amusement Park Heory of Creativity. In J. C. Kaufman \& J. Baer (Eds.), Creativity across Domain: Faces of the Muse (pp. 321-328). Mahwah, NJ: Lawrence Erlbaum Associates.

Lin, W. W. (2006). National Primary and Secondary School Organizational Culture, the Relationship between Teachers and Creative Teaching and Creative Teaching Potential. Taipei: National Chengchi University.

Sawyer, R. K. (Ed.). (2011). Structure and Improvisation in Creative Teaching. New York: Cambridge University Press. http://dx.doi.org/10.1017/CBO9780511997105

Schacter, J., \& Thum, Y. M. (2004). Paying for High and Low Quality Teaching. Economics of Education Review, 23, 411-430. http://dx.doi.org/10.1016/j.econedurev.2003.08.002

Sergiovanni, T. J. (2000). Leadership as Stewardship. “Who’s Serving Who?”. The Jossey-Bass Reader on Educational 
Leadership. San Francisco, CA: The Author.

Simonton, D. K. (1995). Exceptional Personal Influence: An Integrative Paradigm. Creativity Research Journal, 8, $371-376$. http://dx.doi.org/10.1207/s15326934crj0804_3

Simonton, D. K. (2012). Teaching Creativity: Current Findings, Trends, and Controversies in the Psychology of Creativity. Teaching of Psychology, 39, 217-222. http://dx.doi.org/10.1177/0098628312450444

Spears, L. C. (1998). Introduction: Tracing the Growing Impact of Servant Leadership. In L. C. Spears (Ed.). Insights on Leadership: Service, Stewardship, Spirit, and Servant-Leadership (pp. 1-12). New York: Wiley \& Sons.

Sternberg, R. J., \& Lubart, T. I. (1995). Defying the Crowd: Cultivating Creativity in a Culture of Conformity. New York: Wiley \& Sons.

Yeh, Y. C. (2006). Creative Teaching_Past, Present and Future. Taipei: Psychology. 